\title{
Study on Total Factor Energy Efficiency and Energy Rebound Effect in BTH Urban Agglomeration
}

\author{
Feng Ren*, Dinghong Long, Xin Yu \\ School of Business and Administration, North China Electric Power University, \\ Baoding 071003, Hebei Province, China
}

Received: 27 July 2020

Accepted: 14 October 2020

\begin{abstract}
In order to verify the applicability of Khazzoom-Brookes hypothesis in Beijing-Tianjin-Hebei (BTH) urban agglomeration, an undesirable Super-SBM model is constructed to calculate the total factor energy efficiency (TFEE) of the 13 cities in BTH urban agglomeration from 2007 to 2020 and a measurement model of energy rebound effect (ERE) is built to study the energy rebound effect in BTH urban agglomeration. The TFEE-ERE matrix is constructed to cluster the TFEE and ERE of the 13 cities. The results show that there exist great differences in TFEE among the 13 cities in BTH urban agglomeration. Except for Beijing, Tianjin, Qinhuangdao, Tangshan and Cangzhou, other cities' TFEE values are still at a middle-low level with no obvious improvement trend. The development modes of the 13 cities are divided into four categories, and the development road map of TFEE-increase and ERE-decrease for the 13 cities is provided. The framework system, modeling methods and conclusions of this study are of certain significance for related issues in other urban agglomerations, and also of important values for the formulation of energy management related policies.
\end{abstract}

Keywords: total factor energy efficiency (TFEE), super-SBM, K-B hypothesis, rebound effect (RE), Beijing-Tianjin-Hebei (BTH) urban agglomeration

\section{Introduction}

Since the $21^{\text {st }}$ century, the remarkable economic achievement in China has been accomplished by huge energy consumption [1] with great threats to the ecological environment [2], the constraints of energy on the economy and the influence on environment are increasingly obvious. China has become the second

*e-mail: 51851321@ncepu.edu.cn largest economy in the world with the acceleration of industrialization and urbanization, and its total energy consumption has also enhanced fleetly from 1.5 billion tons of standard coal in 2000 to 4.64 billion tons of standard coal in 2018. In a word, China is still the largest energy consumer and carbon emissions emitter in the world, and its extensive use of energy has led to the continuous deterioration of the ecological environment, and fog and haze weather frequently occurred in China, especially in BTH region. As one of the three worldclass urban agglomerations in China and the largest and 
most dynamic region in northern China, the BTH urban agglomeration plays a pivotal role in the development of China's national economy. In 2018, the total economic volume of the BTH urban agglomeration reached 8.5139 trillion Yuan, accounting for $9.45 \%$ of the total in China. Moreover, the BTH region is also the main force of China's energy consumption, it consumed about 455.3 million tons of standard coal in 2017, accounting for $10.14 \%$ of the total energy consumption in China. BTH urban agglomeration is still in the late stage of industrialization with extremely enormous energy consumption.

Facing the severe energy security situation and ecological environment pressure, improving energy efficiency and reducing energy consumption has become a promising approach to the issues. Available researches have indicated that technological progress is a crucial contributor to improve energy efficiency and decrease energy consumption [3-4]. However, Jevons put forward a paradox in the book of The Coal Problems in 1865, that is, although technological progress can improve the utilization efficiency of a certain resource, the final result is not to decrease but to increase the consumption of such resource, which is called the Rebound Effect (RE). The energy rebound effect (ERE) did not receive widespread attention until the 1990s, and relevant researches were normally pursued founded on Khazzoom-Brookes hypothesis [5-6], which holds that the enhancement of energy efficiency affected by technological progress increased rather than reduced energy consumption. Then, how about the total factor energy efficiency in BTH urban agglomeration? Does the energy rebound effect (ERE) exist in this region? It is of far-reaching significance for energy management, energy conservation and emission reduction to calculate TFEE, scientifically analyze the dissimilarity and variation trend of TFEE, and clarify ERE's intensity in the BTH urban agglomeration.

Empirical researches on energy efficiency used to adopt single-factor indicators and ignored the substitution effect of other input factors. Later, academic circles embarked on energy efficiency under the influence of multiple factors, namely total factor energy efficiency. The data envelopment analysis (DEA) method brought forward by Charnes and Cooper can deal with multi-input and multi-output problems. This method and its derived improved models have been commonly applied in the calculation of TFEE. For example, $\mathrm{Wu}$ et al. [7] measured the TFEE of 30 provinces in China with an improved DEA model and provincial panel data. $\mathrm{Wu}$ et al. [8] built a nonhomogeneous input-output DEA model to measure the energy and environmental efficiency of China's industrial sector. Shen et al. [9], Feng et al. [10] respectively used three-stage DEA and four-stage DEA method to evaluate China's energy efficiency. Early researches are, however, limited: the undesirable outputs such as nitrogen oxides, waste water, smoke and dust were not considered, which has an impact on energy efficiency measurement. Thus, a slacks-based measure (SBM) model, proposed by Tone [11], was employed to overcome the limitations of traditional DEA models. Zhou et al. [12], Yu et al. [13] applied the SBM model to investigate China's provincial TFEE and its heterogeneity while considering the impact of an undesirable output. Xiao et al. [14] analyzed the sectoral energy efficiency and its influencing factors in China based on SBM model and panel regression model. Li et al. [15] constructed an SBM model to measure the energy eco-efficiency of manufacturing industry in 30 provinces and cities in China from 2000 to 2016. The researches listed above have acquired positive achievements, but still have some deficiencies, such as the inability to accurately rank multiple effective decision-making units. As a result, the application of combining super-efficiency and SBM model (the superSBM model proposed by Tone [16]) appeared. Yang et al. [17], Li et al. [18], Yang and Wei [19], Sun et al. [20] set up super-SBM models incorporated with Tobit model and Malmquist index to study TFEE and its affecting factors at provincial or regional level in China. In summary, the existing literature rarely study the application of super-SBM model to TFEE calculation of BTH urban agglomeration. So, this paper constructs a super-SBM model to figure out the TFEE of the cities in BTH urban agglomeration using data of recent years, and thoroughly explores its variation tendency and otherness.

Notwithstanding an increasing number of empirical findings regarding the relationship between technological progress and energy efficiency, there is still no broad consensus in the academic community. Cang et al. [21] believed that technological progress has the capability to increase energy efficiency and decrease energy consumption, while K-B hypothesis holds that technological progress will increase energy consumption, not the other way around. The calculation methods of ERE primarily consist of CGE models, classical economic theory models and econometric methods, etc. Li et al. [22] studied the connection between energy subsidy and rebound effect in multifarious situations by establishing a CGE model, and found that ERE existed in China and the rebound effect of electricity was higher than that of the primary energy. Shao et al. [23] discovered that ERE existed strikingly by measuring the ERE of China's economy from 1954 to 2010. In addition, the Solow remainder method would underestimate ERE in majority cases. Feng and Ye. [24] constructed a semi-parametric spatial lag model of panel data to explore regional economic spatial spillover and energy-economic nonlinear relationship, and estimate ERE contributed by technological progress in 29 provinces on the basis of energy output elasticity. The result indicated that ERE was apparent in developed provinces, but not obvious in underdeveloped provinces. On the whole, the majority of literature investigated ERE from the aspect of national level to industrial sectors, however, little literature did 
research on the ERE at the urban agglomeration level, delimiting ERE's development trend, combining ERE and TFEE, and giving the future development route map. In addition, from the perspective of research techniques, both classical economic theory models and the CGE models require estimation of parameters that are difficult to estimate. Different from the previous studies, this paper calculates the contribution rate of technological progress to economic growth via the total factor productivity (TFP) and constructs the ERE estimation model to work out the ERE value of BTH urban agglomeration according to the panel data from 2007 to 2020.

The main work of this study is as follows: (1) Construct a Super-SBM model that allows for the impact of undesired output on the efficiency measurements to be taken into account, and measure the TFEE values in the BTH urban agglomeration; (2) Set up an ERE model to count the ERE values in the BTH urban agglomeration by calculating the contribution rate of technological progress to economic growth; (3) Built TFEE-ERE matrix and summarize four development patterns to evaluate the development stage of each city in BTH urban agglomeration, then put forward the development route map of hoisting TFEE and weakening ERE in the future. The rest part of this study is arranged as follows: The second part is methodology. The third part is the results and discussion. The fourth part is the conclusions.

\section{Methodology}

\section{TFEE Calculation Model}

Suppose there are $n$ decision-making units (DMUs) and each unit has three factors: inputs $x \in R^{m}$, desirable outputs $y^{g} \in R^{r_{1}}$ and undesirable outputs $y^{b} \in R^{r_{2}}$. Matrixes can be defined as: $X=\left[x_{1}, x_{2}, \ldots, x_{n}\right], \in R^{m \times n}$, $Y^{g}=\left[y_{1}^{g}, y^{g}{ }_{2}, \ldots, y^{g}{ }_{n}\right] \in R^{r_{1} \times n}, \quad Y^{b}=\left[\begin{array}{ll}y^{b}{ }_{1}, & y^{b}{ }_{2}, \ldots, y^{b}{ }_{n}\end{array}\right]$ $\in R^{r} 2^{\times n}$. The production possibility set $(P)$ under constant returns to scale can be defined as: $P=\{(x$, $\left.\left.y^{g}, \quad y^{b}\right) \mid x \geq X \lambda, \quad y^{g} \leq Y^{g} \lambda, \quad y^{b} \leq Y^{b} \lambda, \quad \lambda \geq 0\right\}$ the super-SBM is modeled as:

$$
\begin{gathered}
\rho=\min \frac{1-\frac{1}{m} \sum_{i=1}^{m} \frac{s_{i}^{-}}{x_{i k}}}{1+\frac{1}{r_{1}+r_{2}}\left(\sum_{d=1}^{r_{1}} \frac{s_{d}^{g}}{y_{d k}^{g}}+\sum_{u=1}^{r_{2}} \frac{s_{u}^{b}}{y_{u k}^{b}}\right)} \\
s_{d}^{g} \leq \sum_{j=1, j \neq k}^{n} y_{d j}^{g} \lambda_{j}, d=1,2, \ldots, r_{1} \\
s_{u}^{b} \geq \sum_{j=1, j \neq k}^{n} x_{i j} \lambda_{j}, i=1,2, \ldots, m \\
\lambda_{j} \geq 0, s_{i}^{-} \geq x_{i k}, s_{d}^{g} \leq y_{d k}^{g}, s_{u}^{b} \geq y_{u k}^{b}
\end{gathered}
$$

...where $\rho$ is the target efficiency value, $x_{i k}, y^{g}{ }_{a k}, y^{b}{ }_{a k}$ represent input, desirable output, and undesirable output variables, respectively; $s_{i}^{-}, s_{d}^{g}, s_{u}{ }^{b}$ correspond to the slacks in inputs, desirable outputs and undesirable outputs; $\lambda_{j}$ is intensity vector.

\section{ERE Calculation Model}

In this part, we explore whether there is ERE in BTH urban agglomeration or not, and analyzes the effect of technological advance on energy efficiency. According to the definition, ERE is equal to the ratio of increased energy consumption to expected energy saving, which can be expressed as ERE $=\Delta \mathrm{M}^{+}$ $\Delta \mathrm{M}^{-}$, where, $\Delta \mathrm{M}^{+}$represents the increased energy consumption, $\Delta \mathrm{M}^{-}$denotes the expected energy saving. ERE can be divided into five levels: when $\mathrm{ERE}<0$, it means super energy saving; when $\mathrm{ERE}=0$, it means zero rebound and complete saving; when $0<\mathrm{ERE}<1$, it means partial rebound; when $\mathrm{ERE}=1$, it means complete rebound, and the energy saved is absolutely offset; when ERE $>1$, it means reverse effect, that is, not only are the energy savings completely offset, but additional energy consumption is added.

Assume that the economic output in year $\mathrm{t}$ is $E O_{t}$, energy intensity is $E_{t}$, then the energy input can be expressed as $E I_{t}=E_{t} \cdot E O_{t}$. The amount of energy saved by reducing energy intensity due to technological progress in year $\mathrm{t}+1$ is:

$$
\Delta \mathrm{M}^{-}=E O_{t+1}\left(E_{t}-E O_{t+1}\right)
$$

Energy consumption raised by technological progress promoting economic growth in the year $t+1$ is:

$$
\Delta \mathrm{M}^{+}=\sigma_{t+1}\left(E O_{t+1}-E O_{t}\right) E O_{t+1}
$$

...where $\sigma_{t+1}$ is the contribution rate of technological progress to economic rapid.

Most previous studies have used TFP to represent technological progress in a broad sense, and there is evidence of conceptual inconsistencies. This paper obtains the ERE computational formula through utilizing the total factor productivity rate of growth to calculate the contribution rate of technological progress to economic growth.

The TFP growth rate in year $\mathrm{t}+1$ is:

$$
\Delta T F P_{t+1}=\frac{T F P_{t+1}-T F P_{t}}{T F P_{t}}
$$

The economic growth rate in year $\mathrm{t}+1$ is:

$$
\Delta E O_{t+1}=\frac{E O_{t+1}-E O_{t}}{E O_{t}}
$$

Then, the contribution rate of technological advances to economic growth in year $\mathrm{t}+1$ can be expressed as: 


$$
\sigma_{t+1}=\frac{\Delta T F P_{t+1}}{\Delta E O_{t+1}} \times 100 \%
$$

Therefore, the rebound effect led by technological progress in year $\mathrm{t}+1$ can be expressed as:

$$
E R E=\frac{\Delta M^{+}}{\Delta M^{-}}=\frac{E_{t+1} E O_{t}\left(T F P_{t+1}-T F P_{t}\right)}{\left(E_{t}-E_{t+1}\right) E O_{t+1} T F P_{t}}
$$

\section{Results and Discussion}

\section{Data Description}

In this paper, the research interval was set from 2007 to 2020. Data from 2007 to 2017 were selected from the statistical yearbooks released by the National Bureau of statistics. Statistics for the period from 2008 to 2020 are largely unavailable, according to statistics release practice. Given the importance of the recent trends of the research subjects, we used a variety of scientific methods such as average growth rate trend extrapolation, $\operatorname{GM}(1,1)$ model, and quadratic moving average method to predict the 2018-2020 data based on the available statistical data, and selected the prediction results with the minimum errors as the 2018-2020 forecast values. We selected capital, energy, and labor as the three input indicators, GDP (economic output) as the desired output, and $\mathrm{SO}_{2}$ as the undesired output.

(1) Capital investment: take the fixed asset investment of each city from 2007 to 2020 as the capital investment index. The unit is 100 million yuan.

(2) Energy input: use the total energy consumption of each city, which can be obtained by the product of energy consumption per unit of GDP, and the gross regional production to express energy input, including the utilization of raw coal and crude oil and its products, natural gas, electricity and other energy sources. The unit is 10 thousand tons of standard coal.

(3) Labor input: take the total number of urban employment as the labor input indicator, which can be obtained by the sum number of employees in urban enterprises and in urban individual and private enterprises. The unit is 10 thousand people.

(4) Desirable output: annual GDP value is taken as the desirable output indicator. Let the year of 2007 as the base period, and adjust the real GDP through the deflator index. The unit is 100 million yuan.

(5) Undesirable output: Given the availability of data, we choose the industrial $\mathrm{SO}_{2}$ emission directly from the official statistics released by the China Bureau of Statistics as the undesirable indicator. The unit is tons.

Data sources are the China City Statistical Yearbook, China Energy Statistical Yearbook, Hebei Statistical Yearbook, the statistical bulletins of national economic and social development, and statistical yearbooks in various regions.

\section{TFEE Analysis}

Taken advantage of the above input-output panel data, the TFEE values of BTH urban agglomeration during the period 2007 2020 are calculated by employing the Super-SBM model considering the undesirable output. The results are shown in Table 1.

Overall, the majority of the TFEE in BTH urban agglomeration generally locate at medium-low level. Tablel displays that the TFEE values of Tangshan, Qinhuangdao, Cangzhou, Beijing and Tianjin are greater than 1 , and the TFEE values of the remaining cities fluctuate around 0.7. According to Table 1,

Table 1. TFEE Calculation Results of BTH Urban Agglomeration from 2007 to 2020.

\begin{tabular}{|c|c|c|c|c|c|c|c|c|c|c|c|c|c|c|c|}
\hline City & 2007 & 2008 & 2009 & 2010 & 2011 & 2012 & 2013 & 2014 & 2015 & 2016 & 2017 & 2018 & 2019 & 2020 & Average \\
\hline Shijiazhuang & 0.724 & 0.728 & 0.725 & 0.727 & 1.014 & 1.008 & 0.753 & 0.752 & 0.736 & 0.674 & 0.698 & 0.701 & 0.691 & 0.678 & 0.758 \\
\hline Tangshan & 1.117 & 1.122 & 1.065 & 1.073 & 1.120 & 1.090 & 1.099 & 1.106 & 1.069 & 1.077 & 1.188 & 1.110 & 1.115 & 1.120 & 1.105 \\
\hline Qinhuangdao & 1.014 & 1.033 & 1.033 & 1.056 & 1.050 & 1.051 & 1.062 & 1.080 & 1.074 & 1.055 & 1.027 & 1.054 & 1.025 & 1.025 & 1.046 \\
\hline Handan & 0.663 & 0.657 & 0.655 & 0.661 & 0.672 & 0.681 & 0.648 & 0.665 & 0.671 & 0.622 & 0.690 & 0.610 & 0.602 & 0.599 & 0.650 \\
\hline Xingtai & 0.625 & 0.638 & 0.631 & 0.640 & 0.670 & 0.670 & 0.667 & 0.666 & 0.666 & 0.620 & 0.665 & 0.634 & 0.634 & 0.633 & 0.647 \\
\hline Baoding & 0.721 & 0.724 & 0.721 & 0.739 & 0.748 & 0.747 & 0.743 & 0.766 & 0.784 & 0.720 & 0.956 & 0.857 & 0.857 & 0.861 & 0.782 \\
\hline Zhangjiakou & 0.632 & 0.590 & 0.561 & 0.554 & 0.575 & 0.591 & 0.586 & 0.586 & 0.590 & 0.585 & 0.638 & 0.589 & 0.598 & 0.606 & 0.592 \\
\hline Chengde & 0.643 & 0.645 & 0.628 & 0.624 & 0.667 & 0.673 & 0.656 & 0.638 & 0.642 & 0.624 & 0.624 & 0.613 & 0.610 & 0.609 & 0.635 \\
\hline Cangzhou & 1.221 & 1.213 & 1.222 & 1.255 & 1.174 & 1.162 & 1.108 & 1.053 & 1.029 & 1.124 & 1.13 & 1.107 & 1.110 & 1.115 & 1.144 \\
\hline Langfang & 0.741 & 0.756 & 0.748 & 0.747 & 0.735 & 0.738 & 0.740 & 0.774 & 0.742 & 0.718 & 0.709 & 0.716 & 0.701 & 0.687 & 0.732 \\
\hline Hengshui & 1.044 & 0.675 & 0.670 & 0.672 & 0.671 & 0.710 & 0.714 & 0.689 & 0.738 & 0.782 & 1.026 & 1.086 & 1.120 & 1.153 & 0.839 \\
\hline Beijing & 1.348 & 1.464 & 1.416 & 1.454 & 1.601 & 1.610 & 1.620 & 1.685 & 1.777 & 1.729 & 1.776 & 1.779 & 1.781 & 1.784 & 1.630 \\
\hline Tianjin & 0.748 & 0.755 & 1.013 & 1.048 & 1.034 & 1.074 & 1.139 & 1.101 & 1.119 & 1.054 & 1.054 & 1.108 & 1.129 & 1.138 & 1.037 \\
\hline
\end{tabular}


Table 2. The K-means Clustering Results of TFEE in BTH Urban Agglomeration.

\begin{tabular}{|c|c|c|}
\hline Rank & The range of TFEE & City \\
\hline High-efficiency area & $1.30 \sim 1.80$ & Beijing \\
\hline Medium-efficiency area & $1.00 \sim 1.30$ & Tianjin, Tangshan, Qinghuangdao, Cangzhou \\
\hline Low-efficiency area & $0.50 \sim 1.00$ & $\begin{array}{c}\text { Shijiazhuang, Handan, Xingtai, Baoding, Zhangjiakou, Chengde, Langfang, } \\
\text { Hengshui }\end{array}$ \\
\hline
\end{tabular}

the TFEE showed obvious regional differences. The TFEE trends of Beijing and Tianjin appear sharply increases, that of Shijiazhuang rises first and then falls. Nevertheless, and those of other cities remain almost unchanged. Specifically, the TFEE values of Tangshan, Qinhuangdao and Cangzhou are always larger than 1, and those of the rest cities (Handan, Xingtai, Baoding, Zhangjiakou, Chengde, Langfang, and Hengshui) are less than 1.

In order to further analyze the diversity and the variation tendency of TFEE, this paper applied K-means to cluster the TFEE values, and divided 13 cities into three groups: high efficiency, medium efficiency and low efficiency, presented in Table 2. It can be seen from Table 2 that Beijing, the only city in the high-efficiency area, has the highest energy efficiency in each year during the research period, with a value range from 1.300 to 1.800 . Tianjin, Tangshan, Qinhuangdao and Cangzhou, located on the Bohai Bay, are in the medium-efficiency area. Especially, Tianjin, a municipality directly under the central government, has maintained a smooth and progressive development tendency since its TFEE value exceeded 1 in 2009 . The TFEE values of other three cities in the mediumefficiency area are higher than 1 each year. Eight cities have fallen into low-efficiency area, i.e., Shijiazhuang,
Handan, Xingtai, Baoding, Zhangjiakou, Chengde, Langfang and Hengshui, with TFEE values ranging from 0.50 to 1.00 .

In recent years, the BTH urban agglomeration has attached great importance to the use of clean energies and actively adjusted the energy consumption structure. In addition, it has also imposed stringent energy saving and emission reduction policies and continuously upgraded the industrial structure. These measures jointly have been promoting the improvement of TFEE. Even so, spatiotemporal diversities are apparent in the TFEE values among cities. Fig. 1 illustrates the temporal and spatial distribution of TFEE of the 13 cities. The TFEE average values of Beijing from 2011 to 2015 and 2016 2020 are within the range of $1.300 \sim 1.499$, apparently higher than that from 2007 to 2010 within the range of 1.55 1.85. The TFEE values of Tianjin have exceeded 1.00 after 2010, which is closely associated with their higher economic development level and flourishing tertiary industry. The TFEE of Qinhuangdao falls within 1.000 1.299, chiefly profiting from the development of its tourism industry. From 2016 to 2020, the TFEE average values of Baoding and Hengshui are within 0.800 0.999 and $1.300 \sim 1.499$, respectively, comparatively larger than that of prior years. The TFEE values of these cities have

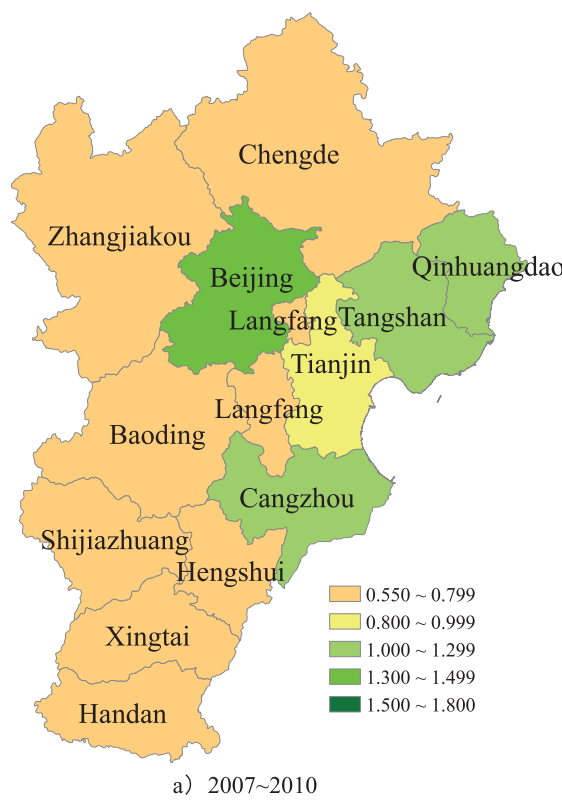

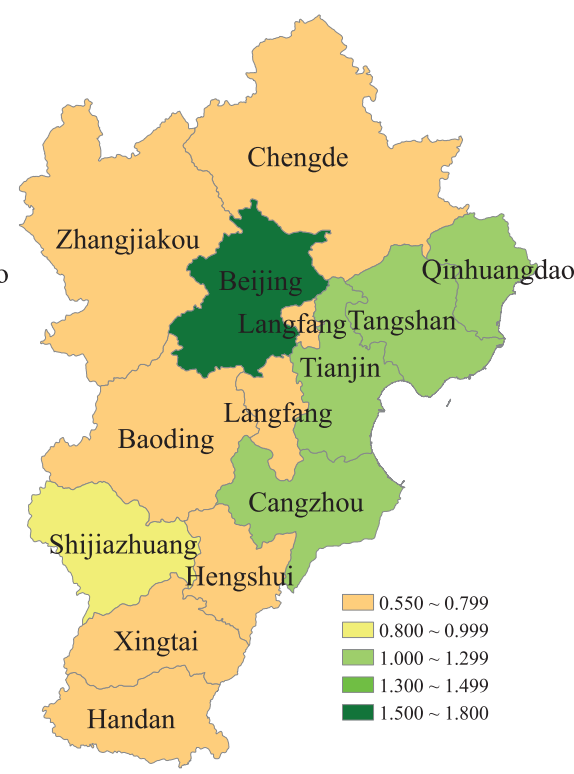

b) 2011 2015

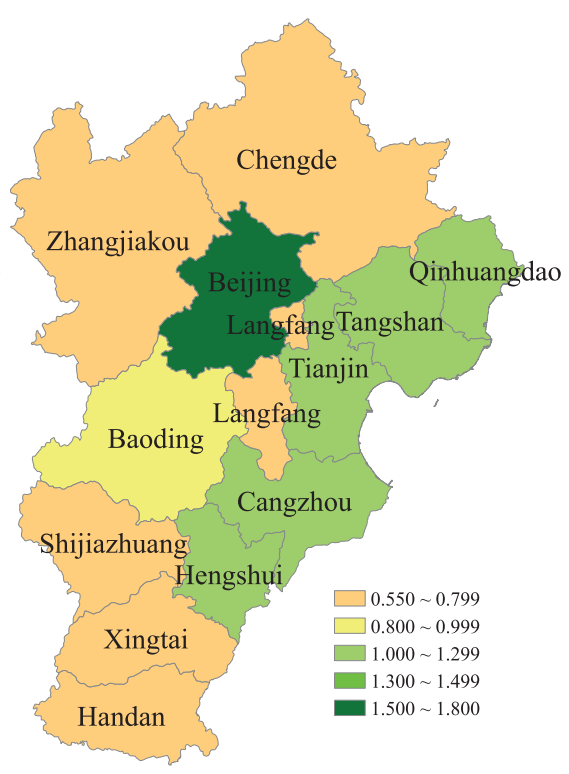

c) $2016 \sim 2020$

Fig. 1. Temporal and Spatial Distribution of TFEE in BTH Urban Agglomeration. 
been improved to a certain extent during 2011 2015 and 2016 2020, that is, during the 12th Five Year Plan and the 13th Five Year Plan, indicating that these cities can timely grasp the opportunities brought by national economic development to actively promote their industrial transformation and upgrading.

Shijiazhuang's TFEE acts the characteristics of first going up and then down, increasing significantly from 2011 to 2015, decreasing slightly after 2016. Shijiazhuang positively tailored the secondary industrial structure during the "Twelfth Five-Year Plan" period, and cut the use of coal, which improved TFEE in the first two years of the "Twelfth Five-Year Plan", and then the large-scale urban reconstruction activities hindered the improving trend of TFEE. The TFEE average values of Tangshan and Cangzhou sit within 1.000 1.299, both of them at a relatively high level in Hebei Province. Tangshan is one of the earliest modern industrial cities in China, and its economic development level (GDP) has always been ranked first in Hebei Province with high energy efficiency. Cangzhou has actively adjusted its economic development structure in recent years, exerted the advantages of facing the Bohai gulf to expand its open economy system. Besides, Cangzhou's high-tech industry has been developed rapidly. TFEE values of Handan, Xingtai, Zhangjiakou, Chengde and Langfang vary in the range of $0.500 \sim 0.799$. Obviously, these cities are relatively underdeveloped, and their traditional secondary industries are drags on their TFEE to some extent.

\section{Analysis of Rebound Effect Measurement Results}

The ERE values of each city from 2008 to 2020 are calculated by formula (7), divided into three intervals based on time: 2008 2011, 2012 2015 and 2016 2020, and then the ERE average value of each interval can be worked out. The calculation results are shown as Fig. 2 (The rebound effect value in 2007 cannot be acquired owe to the time lag).

Fig. 2 shows that ERE exists in the BTH urban agglomeration in general, and the ERE of different cities are quite different. The ERE values of Tangshan, Baoding, Handan and Hengshui show upward trends, and greater than zero during 2014 2017, which means that the additional energy consumption brought about by technological advances has greatly offset the expected energy savings in these cities. Tangshan is the most economically powerful city in Hebei province, and its swift economic growth has also augmented the energy demand. Baoding, Handan and Hengshui are all in the low-efficiency area, and their common characteristic is that traditional secondary industry is dominant in economy structure. For these three cities, technological progress has led to more investment in physical production activities, and energy input partially has replaced labor and capital inputs. The ERE values of Beijing, Langfang, Tianjin, Cangzhou, Shijiazhuang, and Xingtai presents diminishing trends. From 2016 to 2020, the average ERE values of these cities were all less than zero and showed the characteristics of super energy saving, and the ERE was alleviated compared with other years. The average ERE value of Tianjin from 2016 to 2020 was still higher than zero, which means there is a partial rebound effect in energy consumption. As a metropolis in northern China, Beijing has almost the highest level of technological progress during the period 2007 2015, and it has greatly improved its productivity, accelerated its urbanization and enlarged its population. As a result, there has been a tremendous increase in energy demand, and Beijing's energy consumption partially rebounded in 2008-2011 and 2012-2015. In recent

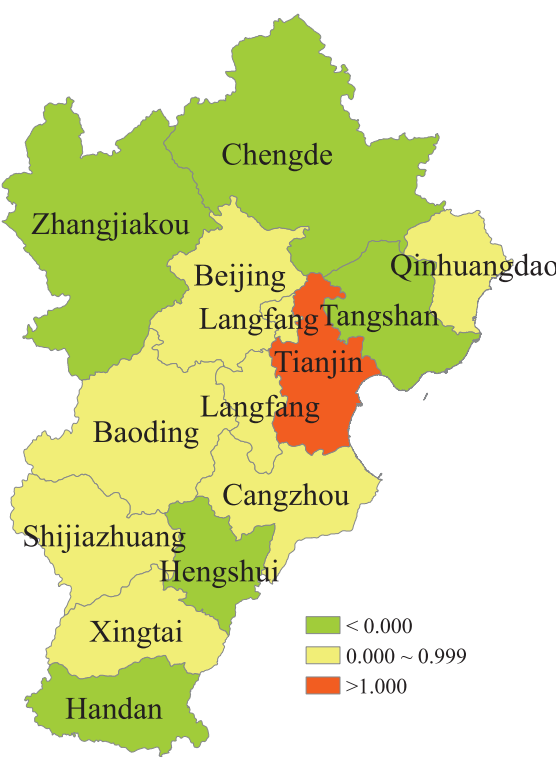

a) $2008 \sim 2011$

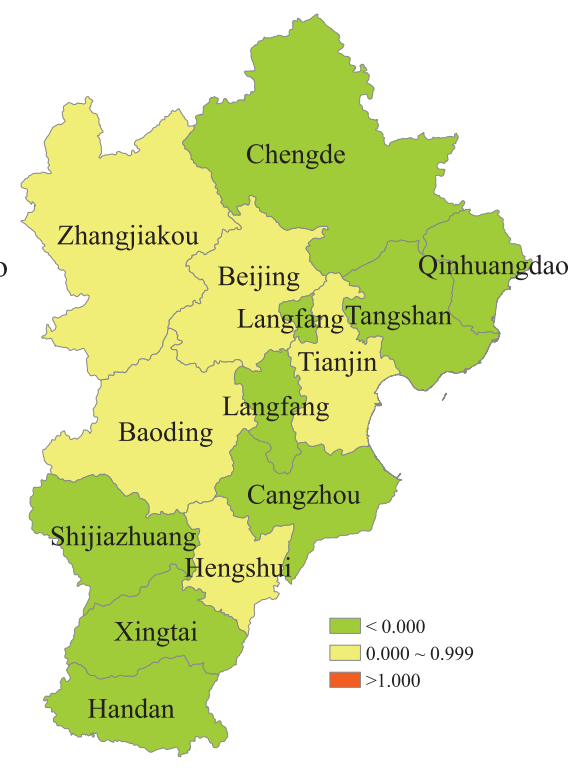

b) $2012 \sim 2015$

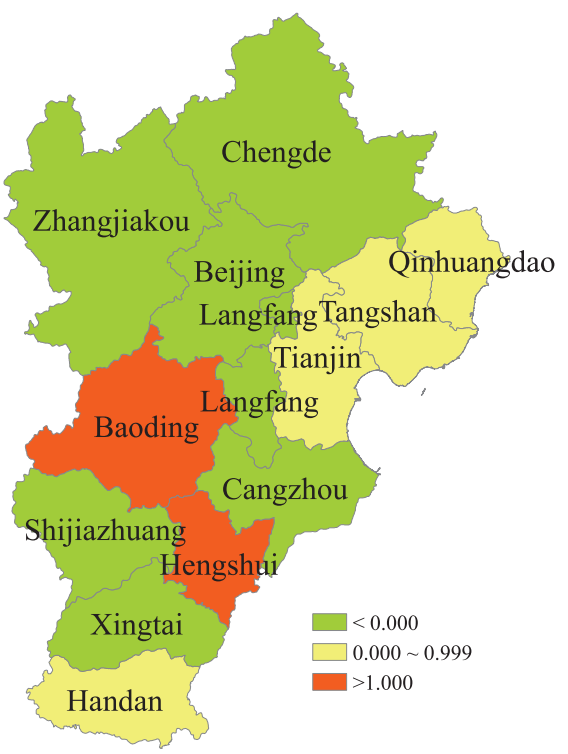

c) $2016 \sim 2020$

Fig. 2. Temporal and Spatial Distribution of ERE in BTH Urban Agglomeration. 


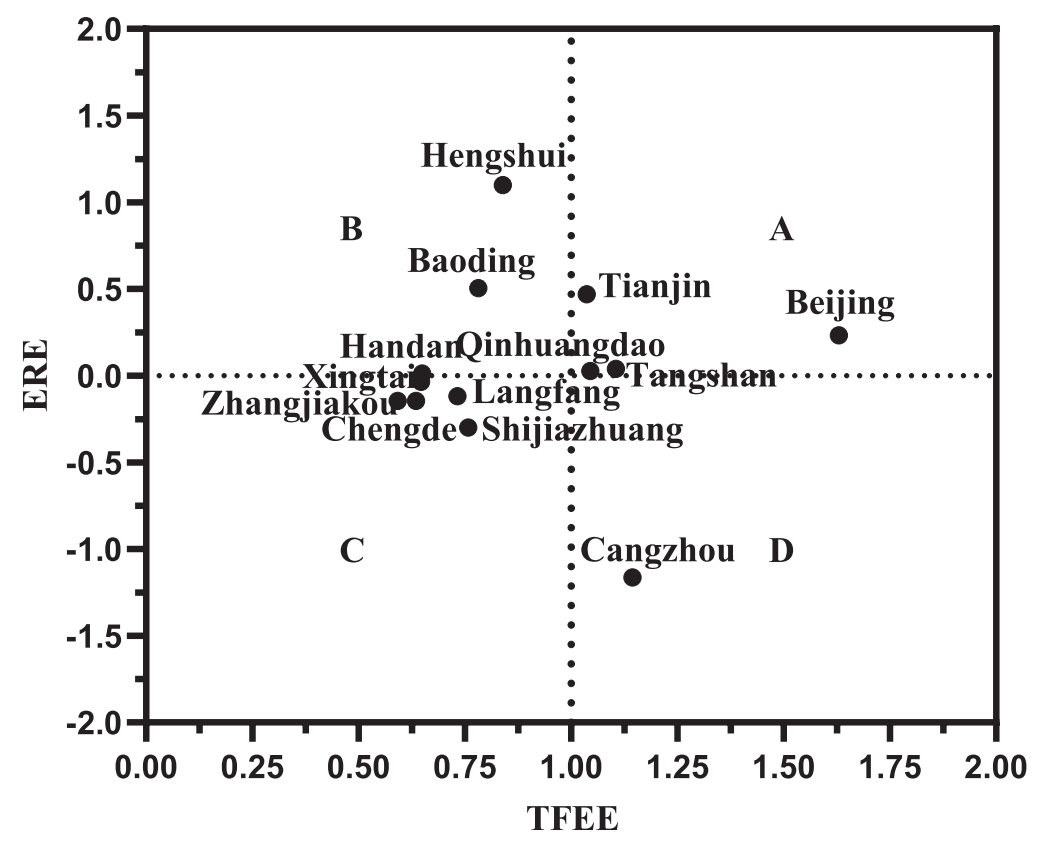

Fig. 3. TFEE-ERE Clustering Diagram.

years, the integration of Beijing-Tianjin-Hebei and the implementation of the Xiong'an New District have brought Shijiazhuang a certain development space and provided opportunities for its industrial transformation and upgrading. Therefore, during the " $12^{\text {th }}$ Five-Year Plan" and " $13^{\text {th }}$ Five-Year Plan" period, Shijiazhuang's energy consumption has been greatly saved. Cangzhou, located in the Bohai Rim region, benefiting from the coastal development advantages, has accelerated the pace of industrial restructuring and upgrading and limited the development of industries with high energy consumption and high pollution, thus its energy saving brought by technological progress has been completely conserved. Langfang is close to Beijing and Tianjin, and the unique geographical position provides conditions to speed up the development of the service industry with low energy intensity. Therefore, its ERE embodies as the super energy-saving type.

\section{The Connection between TFEE and ERE}

In order to further explore the features of TFEE and ERE in BTH urban agglomeration, we classify the 13 cities from two dimensions (TFEE and ERE), and give the TFEE-ERE clustering diagram as Fig. 3.

Fig. 3 displays that Beijing, Tianjin, Tangshan and Qinhuangdao belong to Area A with "high energy efficiency and high rebound". All of these four cities have the TFEE values greater than 1 and the ERE values between 0 and 1. Beijing, Tianjin and Tangshan are economically developed, which makes their demand for energy high. Despite the relatively low level of economic development in Qinhuangdao, the technological advances have reduced the proportion of energy costs, which has led to more energy demand, too. Hengshui, Baoding, Handan are classified as Area B with "low energy efficiency and high rebound". The secondary industries in these cities are energy intensive, so the demand for energy is also very strong. On the one hand, technological advances have improved energy efficiency and increased the energy-output elasticity. On the other hand, the substitution effect of energy on labor force and capital is expanding, which leads to lower energy conservation level than expected. Zhangjiakou, Chengde, Shijiazhuang, Langfang and Xingtai are situated in Area C with "low energy efficiency and low rebound", TFEE mean values less than 1, and ERE mean values lower than zero. Due to the limited development (for example, the siphon effect leads to the concentration of talents and capital into Beijing and Tianjin), investments such as capital and labor in these four cities are insufficient, resulting in few improvement in energy efficiency. Cangzhou is the only city in Area D with "high energy efficiency and low rebound", the TFEE values greater than 1 and the ERE values less than zero, which means that the energy savings brought about by technological progress have been completely conserved. Cangzhou, on the verge of Bohai Sea, has greatly promoted the development of various industries, such as information, software and other high-tech industries. In other words, its economic structure has been optimized and upgraded. When energy demand reaches saturation, the reduction in energy costs resulting from technological advances is minimal.

In general, due to the different levels of economic development, production technology and industrial structure in BTH urban agglomeration, the impact of technological progress on TFEE is significantly different in space and time, as well as ERE. 


\section{Conclusions}

This study calculated the TFEE and ERE of the 13 cities in the BTH urban agglomeration from 2007 to 2020. The relationship between TFEE and ERE is further explored through the two-dimensional cluster diagram. The findings include the following aspects: First, there are significant differences in TFEE between different cities in the BTH urban agglomeration. TFEE calculation results reveal that except for Beijing, Cangzhou, Qinhuangdao, and Tangshan with TFEE values larger than 1 , the rest cities' TFEE values vary from 0.5 to 1.0. Second, judging from the calculation results, the ERE caused by technological progress exists in BTH urban agglomerations as a whole, varies observably among cities, and even shows "reverse effects" in some cities. Third, different cities have significantly differences in the impact of technological progress on ERE and the temporal and spatial distribution characteristics of TFEE. Four cities (Beijing, Tianjin, Tangshan and Qinhuangdao) belong to Area A with "high energy efficiency and high rebound". Three cities (Hengshui, Baoding, Handan) are classified as Area B with "low energy efficiency and high rebound". Five cities (Zhangjiakou, Chengde, Shijiazhuang, Langfang and Xingtai) are situated in Area C with "low energy efficiency and low rebound". Only one city (Cangzhou) is in Area D with "high energy efficiency and low rebound". From TFEE-ERE clustering diagram, we can see that the city in Area D has the best development trend, followed by those in Area A and Area C, and cities in Area B are the worst off. Therefore, we propose a roadmap for urban energy efficiency development in the BTH region. The aim vision for cities in BTH urban agglomeration should be as follows: most cities are located in Area D with high TFEE and low ERE. Therefore, the future direction of efforts should be as follows: Cities in Areas A, B and C should gradually strive to be closer to Area D by formulating and implementing scientific policies and strategies.

In the light of the roadmap mentioned above, this paper gives the following suggestions: (1) Further optimize the industrial structure. Compared with Beijing and Tianjin, Hebei province's industrial structure is "heavy" (energy-resource-intensive industries), and the service industry also has a large space for development. So, cities in Hebei province should sustain to bend their efforts for the optimization of industrial structure and promote the development of the tertiary industry vigorously. Energy-inefficient cities need to make great efforts to transform and upgrade their traditional manufacturing industries, and take the opportunity of industry 4.0 to accelerate the deep integration of traditional manufacturing and service industries with informatization, automation and artificial intelligence. In addition, BTH urban agglomeration should strive to jointly develop modern manufacturing and service industries with high technological content and high added value of labor, so as to become the twin engines driving economic development. (2) Government intervention and market regulation go hand in hand. Cities should strengthen their investment review systems for government projects to reduce duplication of construction and inefficient energy use caused by bad decisions. Municipal authorities should strengthen macro-control and moderately relax their direct intervention in the market. Moreover, enterprises with high energy consumption and high pollution should be phased out to promote the rational allocation of resources by improving the market supervision mechanism and creating an effective market competition environment. (3) Improve environmental laws and regulations and optimize the energy mix. Cities should strengthen environmental protection legislation and clarify the environmental responsibility of enterprises. Municipalities should strictly control the emission of pollutants such as nitrogen oxides and increase penalties for environmental pollution. Besides, strategic investment in energy conservation and environmental protection industries should be augmented reasonably. Enterprises with high energy consumption should vigorously increase the use of renewable energy such as wind, hydropower and biomass and reduce the use of primary energy such as coal and oil. These measures will further promote energy conservation and emission reduction in the production sectors. (4) Reduce the energy rebound effect (ERE). The existence of ERE indicates that the expected goal of energy conservation cannot be achieved only by relying on technological progress, and needs to be coordinated with other policies and measures. However, we should also note that ERE values in most cities are less than 1, which means that technological progress is still a booster for energy conservation. Cities should stimulate energy efficiency management, energy conservation and emission reduction through technological progress, government regulation and energy price reform, and continue to implement carbon tax and clean energy subsidy policies. Practice has proved that the implementation of environmental policies can reduce the energy consumption and carbon emissions to a certain extent. Furthermore, advancing energy price reform and increasing energy consumers' sensitivity to energy prices can also weaken ERE to some extent, too.

In this paper, TFEE and ERE are adjoined to study the temporal and spatial distribution in BTH urban agglomeration. The development stages of each city are deeply analyzed by TFEE-ERE matrix, and the evolution roadmap of energy conservation and emission reduction in the future is proposed. However, there are still some deficiencies in our study. Only one undesired output is considered; Only the quantity of labor input is considered, not its quality; The factors that influence energy efficiency are not considered comprehensively; The roadmap for improving energy efficiency and energy rebound effect needs further improvement, and 
so on. The deficiencies above can be solved in future research.

\section{Acknowledgements}

We gratefully acknowledge the financial support from the Hebei Social Science Fund (HB17GL068) and the Fundamental Research Funds for the Central Universities (2018MS143).

\section{Conflict of Interest}

The authors declare no conflict of interest.

\section{References}

1. NAMINSE E.Y., ZHUANG J.C. Economic Growth, Energy Intensity, and Carbon Dioxide Emissions in China. Polish Journal of Environmental Studies. 27 (5), 2193, 2018.

2. WU M.R., ZHAO M. The Dynamic Relationship between Energy Consumption, Environmental Pollution and Economic Growth - Based on the Time Series Data of China from the Year 1990 to 2014. Journal of Technical Economics \& Management. 12, 25, 2016.

3. ZHU W.N., ZHANG Z.H., LI X.D., FENG W., LI J.F. Assessing the effects of technological progress on energy efficiency in the construction industry: A case of China. Journal of Cleaner Production. 238, 2019.

4. ZHANG Z.H., JIN J., XU J.Y. Analysis of the Effect of Technical Innovation on Energy Consumption in the Context of New Normal Economy - A Case Study in Beijing. Science\&Technology and Policy. 33 (07), 7, 2016.

5. KHAZZOOM J.D. Energy savings from the adoption of more efficient appliance Energy Journal. 3 (1), 117, 1987.

6. BROOKES L. Energy efficiency and economic fallacies. Energy Policy. 28 (2), 199-201, 2000.

7. WU J., TAN T., YANG K., YANG J. China' Total Factor Efficiency Evaluation - Based on Nonseparable ThreeStage DEA Model. Journal of Applied Statistics and Management. 38 (03), 418, 2019.

8. WU J., LI M.J., ZHU Q.Y., ZHOU Z.X., LANG L. Energy and environmental efficiency measurement of China's industrial sectors: A DEA model with non-homogeneous inputs and outputs. Energy Economics. 78, 468, 2019.

9. SHEN N., ZHOU J.J., ZOU W.J. Energy Efficiency Measures and Convergence in China, Taking into Account the Effects of Environmental and Random Factors. Polish Journal of Environmental Studies. 24 (1), 257, 2015.

10. FENG W., YAO X.L. The Evaluation of Green Total Factor Energy Efficiency in China Based on DEA-four Stage. Mathematics in Practice and Theory. 48 (23), 24, 2018.
11. TONE K. A slacks-based measure of efficiency in data envelopment analysis. European Journal of Operational Research. 130 (3), 498, 2001.

12. ZHOU S.J., CHEN Q., SU W.L. Energy Environmental Efficiency Analysis on Chinese Provincial Regional Based on SBM Model. Journal of Quantitative Economics. 33 (01), 57, 2016.

13. YU J.Q., ZHOU K.L., YANG S.L. Regional heterogeneity of China's energy efficiency in "new normal": A metafrontier Super-SBM analysis. Energy Policy. 134, 110941, 2019.

14. XIAO C.M., WANG Z., SHI W.F., DENG L.C., WEI L.Y., WANG Y.W., PENG S. Sectoral energy-environmental efficiency and its influencing factors in China: Based on S-U-SBM model and panel regression model. Journal of Cleaner Production. 182, 545, 2018.

15. LI G., LIU J.G., LI T.Q. Regional Differences of Energy Eco-efficiency in Manufacturing Industry under Consideration of Undesirable Outputs Based on the SBMTobit Two-Stage Model. Chinese Journal of Management Science. 27 (11), 76, 2019.

16. TONE K. A slacks-based measure of super-efficiency in data envelopment analysis. European Journal of Operational Research. 143 (1), 32, 2002.

17. YANG T., CHEN W., ZHOU K.L., REN M.L. Regional energy efficiency evaluation in China: A super efficiency slack-based measure model with undesirable outputs. Journal of Cleaner Production. 198, 859, 2018.

18. LI H., SHI J.F. Energy efficiency analysis on Chinese industrial sectors: an improved Super-SBM model with undesirable outputs. Journal of Cleaner Production. 65, 97, 2014.

19. YANG Z.S., WEI X.X. Total factor energy efficiency of the regions along the belt and road: Measurement, decomposition and influence factors analysis. China Environmental Science. 38 (11), 4384, 2018.

20. SUN X.M., ZHANG H., WANG G. Evaluation of Regional Carbon Emissions Performance Based on SE-SBM Model: Taking Shandong Province as An Example. Ecological Economy. 32 (05), 68, 2016.

21. CANG D.B., WEI X.P., CAO M. Mutil-factors Analysis of China's Fossil Energy Consumption - Based on New Energy Substitution and Energy Technology Progress. Journal of Applied Statistics and Management. 39 (01), 1, 2020.

22. LI H., BAO Q., REN X.S., XIE Y.T., REN J.Z., YANG Y.K. Reducing rebound effect through fossil subsidies reform: A comprehensive evaluation in China. Journal of Cleaner Production. 141, 305, 2017.

23. SHAO S., HUANG T., YANG L.L. Using latent variable approach to estimate China's economy-wide energy rebound effect over 1954-2010. Energy Policy. 72, 235, 2014.

24. FENG F., YE A.Z. Does the Rebound Effect Exacerbate the Increasing of China's Total Energy Consumption? The Journal of Quantitative \& Technical Economics. 32 (08), 104, 2015. 